\title{
Three Independent Factors in Epistemology
}

\author{
Guy Axtell and Philip Olson
}

\begin{abstract}
We articulate John Dewey's "independent factors" approach to moral philosophy and then adapt and extend this approach to address contemporary debate concerning the nature and sources of epistemic normativity. We identify three factors (agent reliability, synchronic rationality, and diachronic rationality) as each making a permanent contribution to epistemic value. Critical of debates that stem from the reductionistic ambitions of epistemological systems that privilege of one or another of these three factors, we advocate an axiological pluralism that acknowledges each factor as an independent "spring" of epistemic value within responsible inquiry.
\end{abstract}

\section{Introduction}

In his 1930 essay, "Three Independent Factors in Morals," John Dewey argues that normative ethical theories struggle to do justice to moral experience, routinely falling short in the tasks they take themselves to perform when their proponents insist unnecessarily upon the conceptual or explanatory primacy of any one of three "factors" that an agent must weigh during moral deliberations. The three factors that he identifies are the facts pertaining to either (a) "principles" (the Right), (b) "consequences" (the Good), or (c) "approbations and disapprobations" (virtue and vice). It is an initial privileging of one or another of such factors that gives rise to our main contrary systems of normative ethics. This strife of systems is possibly unavoidable, but in order to be true to moral experience an agent's "reflective morality" has to recognize the elliptical nature of evaluations of agents and their actions in terms of $\mathrm{a}-\mathrm{c}$; it more specifically has to recognize the partial or limited perspective that reflection on each factor provides, which it is able to do through acknowledging the independence of the intuitions that motivate each such system of normative ethics.

Dewey's moral philosophy as he developed it during and after the 1930's is not only non-reductionistic in this sense of being deflationary about debates between consequentialists, deontologists and virtue theorists as competing "complete" accounts of normative ethics; he was also explicitly pluralist in his own account of reflective morality, as he held that reflective morality is 
improved by employing resources from all three of the systems of normative ethics in the reflection and judgment that is called for when the agent faces a morally problematic situation.

Dewey's "Three Independent Factors" (hereafter TIF) paper proved seminal in the development of his mature theories of value and reflective inquiry, especially in his most productive decade of the 1930s, which produced Logic: The Theory of Inquiry (1938) and in Theory of Valuation (1939). The task Dewey set for himself in TIF guided the development of the second edition of his Ethics and subsequently informed his theory of inquiry and his "general theory of value." Dewey's aim was to look beyond the competing "one-sided" systems in search of a single way to order normative ethical theory; it was to ask what would aid our actual practices of inquiry, reflection, and judgment, and "what permanent value each group contributes to the clarification and direction of reflective morality" ( $L W 7,183)$.

In this paper we identify and describe three factors - in no small degree the epistemological analogues of the Good, the Right, and Virtue in ethical theory - that we recognize as each contributing to epistemic goodness or value. These different "springs," to use Dewey's metaphor, are (1) agent reliability (the causal etiology of belief), (2) synchronic epistemic rationality (one's attitude towards a given proposition "fitting" one's total evidence at any time-slice), and (3) diachronic epistemic rationality (epistemic responsibility across time; responsibility in inquiry or evidence-gathering). The groups that insist on the conceptual primacy or epistemic centrality of one or another of these factors in the evaluation of epistemic agents and their beliefs also give rise to competing "systems" offering contrary accounts of epistemic value or goodness: most naturally these are the systems of reliabilist externalism, evidentialist internalism, and virtue epistemology. These groups typically also take themselves to be offering "complete" accounts of epistemic goodness, while the present approach views them as one-sided theories whose reductive ambitions are doubtful, and which when allowed to fester often side-track philosophers onto counter-productive focuses of debate. Inspired by Dewey's non-reductive, "independent factors" approach to moral philosophy, we will want to extend his methodology in order to propose and to answer analogous questions with respect to the main competing accounts of epistemic normativity: What "permanent value" does each of our epistemic analogues contribute to the clarification of the sources of epistemic value and to the direction of our intellectual inquiries?

Dewey was explicitly concerned with a theory of inquiry encompassing both moral and intellectual problems, and with a "general theory" of value or valuation not restricted to moral judgment or practical reason. There are of course many important differences between moral and epistemic goodness that indicate the need for different treatment. But these differences do not on our view stand in the way of our applying Dewey's method to the debate about philosophic normativity, nor do they hinder our asking the specific analogue question about what permanent value each factor identified above contributes to 
the clarification of epistemological goodness. Like Dewey, we start out critically before moving to the constructive part of our project. We ultimately want to support both a non-reductionist philosophical methodology and an explicitly pluralist epistemological axiology, but supporting the latter requires additional steps beyond the criticisms we will offer of reliabilist externalism, evidentialist internalism, and certain ("robust") forms of virtue or character epistemology. We will first clarify Dewey's anti-reductionistic methodology and the ways he applied it to the problems facing reflective morality (Section 2). This puts us into position in the subsequent sections 3-6 to develop our own epistemic analogue to Dewey's approach. These analogues are our own, and we do not presume that the three factors we explicate through attention to recent debate over epistemic value or goodness are necessarily one's that Dewey would himself identify if he were privy to recent central debates in epistemology.

In our concluding section 7 we summarize and then turn our attention to the more constructive aspects of our project, and more specifically to the philosophic support of a version of epistemic value pluralism that we term axiological pluralism. We call it such because it makes a claim about the plurality of sources of epistemic goodness or value, rather than about an irreducible plurality of specific cognitive aims (understanding, wisdom, justification, etc.) beyond the aim of true belief and/or knowledge that epistemic value monists (veritists) take as a core aim of our intellectual lives. This recalls the distinction between axios (worth or value) and telos (aim or ultimate end). Our approach is consistent with epistemic value pluralism in the latter and more usual sense focusing on aims (a form of pluralism which we have each argued for elsewhere); but it is intended to open discussion of this more challenging kind of pluralism and its implications for epistemology. In developing axiological pluralism, we are aided by attention to Dewey, Peirce, James, and a longer "agent" and "inquiry"-focused tradition of American pragmatism. This approach we think also helps articulate and support recent calls for "valuedriven" epistemology (Kvanvig, Pritchard), or at least provides some new resources helpful to addressing problems related to what Wayne Riggs calls the "family of credit-related" epistemic concepts, including faculty virtues, reflective virtues, epistemic responsibility/credit, meta-cognitive control, and epistemic luck of certain kinds.

\section{The 'Three Factors' Essay in the Development of Dewey's Ethics}

As mentioned earlier, Dewey criticized consequentialism, deontology and virtue ethics as "one-sided" accounts that as such cannot provide the complete account of reflective morality that their proponents typically take themselves to provide. His own familiarity with Aristotelianism helped him to anticipate "virtue ethics" as a third system in addition to those of "rules" and of "ends," decades before its "official" revival in Anglo-American philosophy in the early 1960s; but while it informs his constructive accounts of habits of inquiry and of the relationship 
between moral and intellectual flourishing, he was also clear in wanting to undercut virtue theory in any narrow sense as just another "opposing system" in addition to the long-standing contrast of the morality of ends and the morality of laws. According to Dewey, "there are at least three independent variables in moral action" ( $L W 5,280)$, none of which can be reduced to the others. The good, which has to do with objects that satisfy desires, is entwined with the concepts of reason and ends. Reason is the faculty by which we reflectively project desired ends and compare their relative values. The idea of the good emerges at the top - as the most desirable - through the organization and ranking of ends with respect to their relative values. Independently of the good, the right, too, is a source of moral value. The right, which arises as a result of the reciprocally recognized demands that we make upon one another's conduct, requires "the emotional and intellectual assent of the community" (282). As such, the right transforms the more individualistic concepts of "good" and "end," infusing them with the socially generated and socially sustained authority characteristic of "being right." Finally, virtue and vice provide a third independent source of moral value. The concepts of virtue and vice capture the generalized content of "widespread" approbation and disapprobation. Virtue and vice are initially spontaneous or pre-reflective reactions to others' actions; they occur independently of the "immediate social pressure characteristic of the right" (286) but are later tested against and shaped by those pressures.

The independence of these three factors (the good, the right, and habits of virtue and vice) does not imply that they don't all constitute a part of any moral situation. In fact, Dewey claims that each is a part of "all actual moral situations" (287). This is important, for the presence of each of the three factors as weighing into a given moral agent's situation means that "they can be at cross purposes and exercise divergent forces in the formation of judgments" (280). From Dewey's perspective, "[t]he essence of the moral situation is an internal and intrinsic conflict; the necessity for judgment and for choice comes from the fact that one has to manage forces with no common denominator" (ibid.) Dewey would applaud Rosalind Hursthouse's insistence that we should not assume "that any adequate action-guiding theory must make the difficult business of knowing what to do if one is to act well easy, that it must provide clear guidance about what ought not to be done which any reasonably clever adolescent could follow if she chose" (Hursthouse 1991, 230-231). By contrast, Dewey argues that, "it is characteristic of any situation properly called moral that one is ignorant of the end and of good consequences, of the right and just approach, of the direction of virtuous conduct, and that one must search for them" ( $L W 5$, 280). Indeed, it is precisely this search that gives reflective moral life the meaning, urgency, and flavor that it has for us.

These Deweyan themes are developed some years later in the second edition of Dewey and Tuft's Ethics. There, the shift from customary to reflective morality puts the burden on the individual, making it the first business of ethics to get an outline of the factors that constitute personal disposition. But Gregory 
Pappas is right to ask the Deweyan question: "Why must moral theorists decide if becoming a good character or doing the right actions is the end of our moral life?" (Pappas 2008, 133). Against what he calls the "'doctrine of fixed means and ends," Dewey argues that there are no fixed means and ends in moral life, and thus no good reason to take either character considerations (virtues, ideals, projects) or act considerations (rules, principles, consequences) as the defining paradigm of moral engagement. For even though the landscape of moral conceptions - including desires, social demands, and approbation and disapprobation - are "constant" and "fundamental" parts of our moral lives, the particular emphases that theories or even cultures take on, in response to particular concerns and circumstances, are transient.

Dewey's approach contains a metaphilosophical view about the strife between systems of ethics as often under-motivated, and debates over the conceptual primacy of one or another of the three factors in particular as based on selective emphasis. But there is a constancy and fundamentality of the moral framework Dewey provides through his unique, non-reductive stance. So long as one is willing to treat theories as tools, and alternative models as not incompatible resources for moral reflection and judgment, the alternative systems we have come to know as deontology, consequentialism, and areteic ethics have value for reflective agents due to the unique resources each model provides for reflection on difficult issues.

\section{Three Independent Sources of Epistemic Value}

If our approach provides the useful resources that we think it does, we should be able to fill in our epistemic analogue of Dewey's approach by identifying multiple factors that independently or in conjunction contribute to epistemic value. Their "independence" as sources of epistemic value is something that will need to be argued for, but identifying these factors requires us only to look to the master intuitions driving contemporary debate about the nature and sources of epistemic value. We identify these as three, though some might argue there are even more:

First: Agent reliability. Reliability in the production and maintenance of epistemic goods such as knowledge and understanding is an epistemic good. Today, this good is typically associated with externalist or truthlinked accounts of knowledge and/or justification, including safety-based anti-luck epistemologies that focus on the reliable production of belief together with the exclusion of veritic externalist luck, the luck the comes 'betwixt belief and the fact,' as we witness in Gettier cases.

Second: Synchronic epistemic rationality. To have toward a proposition a doxastic attitude that 'fits' the evidence evokes a kind of epistemic rationality that is a source of epistemic value. Evidentialist internalism "is 
a theory of synchronic epistemic rationality" according to its best-known proponents, E. Conee and R. Feldman. But personal epistemic justification of this sort is valuable even independently of the links that internalists claim it has to an agent's having epistemic justification and propositional knowledge. We are in good epistemic circumstances and succeeding in a sense when we can offer internalist justifications of our beliefs.

Third: Diachronic epistemic rationality. Personal justification in this sense concerns habits of inquiry across time, including motivational components in knowing and the agent's selection and utilization of strategies appropriate to their problem situation. This personal justification evokes a kind of epistemic rationality related to responsbility in inquiry and belief maintenance/change; it gets its value from the exemplification of virtue in the sense of responsible actions and motivations in an agent's initial and continuing intellectual inquiries. We interpret virtue responsibilism of the inquiry-focused (hereafter inquiry pragmatist) variety as a theory of diachronic rationality. The reflective intellectual virtues are enduring, praiseworthy traits that manifest in responsible actions-at-inquiry; good habits of inquiry are productive of states of internal justification and dispositions to believe reliably; but as personal virtuosity one's diachronic rationality also contributes to the character development or "growth" of the agent; the exemplification of intellectual virtues also has value because the exercise of virtue is partly constitutive of intellectual flourishing.

Let us now turn to a further explication of the role each of these factors plays in agent and belief evaluation, and of what is meant by the claim that each constitutes an "independent spring" of epistemic goodness or value.

\section{Agent Reliability and Externalist Luck}

Since Gettier, discussion of the problem of epistemic luck has become considerably more sophisticated as epistemologists like Duncan Pritchard have identified distinct kinds of epistemic luck and attempted to clarify how each differently impacts our capacity for knowledge or for other epistemic goods. During 2003-2005 Pritchard's anti-luck epistemology was strongly externalist and reductionist, and his "safety-based," counter-factualist approach did not require a condition for the reliability of the belief-forming process at all, let alone a condition of believing truly from abilities or competencies as virtue epistemologists understand them: "[T]he appropriate moral to draw ... does not seem to be that we need to keep supplementing the reliabilist thesis ad infinitum ... but rather that we should simply accept that knowledge is, at root, just true belief that meets the safety principle" (Pritchard 2003, 119). 
“Anti-Luck" epistemology had reductionist ambitions, and exemplified one version of reductionism based upon the first factor. One of Pritchard's aims in Epistemic Luck (2005) was to show a redundancy and therefore an overall lack of motivation in virtue epistemologies. In more recent papers he appears to have found his own motivation for an areteic condition: alongside of his "Master Intuition" regarding "the incompatibility of knowledge and luck," he now concedes a second Master Intuition, namely an intuition regarding "the centrality of cognitive abilities to knowledge." His acknowledgement of this second intuition goes together with the value-driven concern that since the realization of most epistemic goods (understanding at least, but possibly knowledge as well) is a cognitive achievement on the part of the agent, the agent's habits and abilities are the bearers of the "final value" found in achievements of all kinds (intellectual or otherwise). Achievements are made possible through abilities/competences, so that if we are concerned that our accounts of key epistemic goods like knowledge, justification, understanding etc. reflect a sound philosophy of epistemic value, then we will necessarily be concerned with an account of achievements and the habits and abilities through which they are realized. Considerations along these lines led Pritchard, if we interpret him correctly, to respond to criticisms of his austere safety-based or "anti-luck epistemology," which he conceived as a competitor to virtue epistemologies, by giving it up in favor of the "anti-luck virtue epistemology" (2009a, 2009b) he defends today.

This newer stance is nevertheless consistent with Pritchard's continued criticism of "robust virtue epistemology" as a reductionistic option at the other end of the spectrum. Thus, he argues against the claim of "Robust VE" (as an analysis of knowing) that the notion of the agent having a true belief 'because of virtue' can or should be strengthened in such a way that it entails truth and thereby precludes regettierization.

Our own responsibilist approach shares some of Pritchard's scepticism about Robust VE. Moreover, it helps to maintain and elaborate the moderate VE stance that Pritchard prefers - VE with an independent externalist anti-luck condition. In other words, the independence thesis works to move us away from anti-luck and virtue epistemologies taken as mutually-exclusive accounts of knowledge, to anti-luck and virtue epistemologies "in consonance" (Axtell 2007; compare Napier 2008). By robust VE, Pritchard identifies a questionable shared assumption in the approach to knowledge analysis taken by Greco, Napier, Sosa, and Zagzebski: namely, that the areteic condition can 'go it alone' as an anti-Gettier condition, and needn't be supplemented by any more straightforwardly modal anti-luck condition like a safety (or sensitivity) condition. Anti-luck virtue epistemology is "moderate" because it resists the reductionistic claim that the work of a safety condition and an areteic condition can be 'reduced' one way or the other; it acknowledges that what serves to exclude Gettier (veritic) luck or to render our beliefs modally safe (and/or sensitive) is epistemically valuable. 
This is a considerable shift for Pritchard away from his earlier stance as an anti-luck reductionist who conceived knowledge as at bottom just safe true belief. But in addition to seeing a place for an independent areteic condition to address value-driven considerations and epistemic achievements, Pritchard also began distinguishing between "veritic luck," as operating in true Gettier cases, and "environmental luck," as operating in, for example, barn façade cases (Pritchard 2007). Kelly Becker's work may be briefly introduced to further develop the point, because like Pritchard he acknowledges that "externalist luck" has two distinct knowledge-precluding forms, which he calls "world luck" and "process luck." Being thus distinct, each kind of luck requires different treatment: To deal with world or environmental luck, we need a modalized tracking principle, as "a belief-truth linking condition that applies to individual instances of belief formation" (Becker 2008, 356). But process luck requires that we distinguish this narrowly-typed disposition from a principle that would utterly lack generality by applying only to individual belief tokens. So if there is more than one kind of externalist luck that an adequate account of knowledge (or understanding) must preclude, then this makes the reductionistic thesis of robust VE all the more doubtful; an areteic condition may arguably bear upon if not preclude the veritic luck operating in Gettier cases, yet it seems largely irrelevant to the preclusion of what Becker calls world luck and what Pritchard terms environmental luck.

Now some of the best-known proponents of VE like John Greco concede environmental luck to be knowledge-precluding. Our "argument from environmental luck" thus reinforces our thesis that anti-luck concerns are one independent factor in epistemology. According to this argument, defenders of robust VE have done little to show that this anti-luck concern (environmental luck) can be handled well by their areteic condition, even if, as they argue, this condition is all one needs to address veritic luck (i.e., to preclude regettierization). We take the argument from environmental luck to show that the robust virtue epistemologies of Greco, Sosa, and Zagzebski, (compare what Michael Levin calls "motive reliabilism" (Levin 2004)), cannot use fulfillment of the areteic condition to preclude all the forms of externalist luck that an account of knowledge should be concerned to preclude. Our argument underlines the need for an independent anti-luck condition to address environmental luck even if the proponent of robust VE can demonstrate that knowledge "because of virtue" serves to adequately preclude re-gettierization. If this is correct we need our externalist luck condition to remain "independent" of the areteic principle - we need what Pritchard calls "anti-luck virtue epistemology."

Our "independent factors" approach is therefore in Pritchard's terms a "moderate" rather than a "robust" virtue epistemology, which fits our description of our approach as non-reductionist. But as we will later see, ours is a form of (anti-luck) virtue epistemology wherein the responsibilist focus on diachronic traits - what Dewey's called habits and dispositions - plays a very significant role over and above the standard internalist pre-occupation with time- 
slice analysis and with what Conee and Feldman term synchronic epistemic rationality.

\section{The Epistemic Value of Synchronic Rationality}

To be in epistemic circumstances where internalist justification for some target proposition is possible for the agent, and where the agent is able to access the reflectively good reasons that ground her belief, is epistemically desirable. It is good to be in such circumstances, even if such circumstances are not a general necessary condition for propositional knowing (i.e., knowing that). This is really enough to support the contribution that synchronic epistemic rationality makes to epistemic value, even without insisting that such rationality forms a general necessary condition on knowledge. It is enough that internalism is basically on track as an account of what conditions are epistemically most desirable, and what factors determine subjective appropriateness (Greco 2005, 259). There is a kind of intrinsic value to holding the propositional attitude doxastically most appropriate, additional to the instrumental value in obtaining knowledge (or at least one kind of knowledge) (Dougherty 2008).

Making sense of synchronic epistemic rationality's “permanent contribution" to epistemic value is difficult, though, for this requires disengaging it from the internalist's form of reductionism, and disentangling it from the voluntaristic and deontological associations it has in Conee and Feldman's thought. Evidentialism as Conee and Feldman present it is a theory of synchronic epistemic rationality. As an account of what constitutes epistemic justification, we view this as misguided. While our previous section included a criticism of Greco's robust VE, here Greco seems right: if we are to rightly understand epistemic responsibility and personal justification, then "etiology matters." But since our problem is only with the reductionist claim that the kind of rationality that pre-occupies the evidentialist provides a complete account of epistemic rationality, we are still able to allow synchronic epistemic rationality to be a genuine contributor to epistemic value.

Internalist evidentialists tell us that if an agent $\mathrm{S}$ has any attitude towards a proposition, then $S$ "epistemically ought to have the attitude towards $p$ supported by S's evidence at t" (Conee and Feldman 2004, 178). According to the internalist evidentialist, abiding this norm - being synchronically rational maximizes epistemic value and constitutes epistemic success for an agent (2004, 185 ). But the view that you are being a completely or ideally rational agent just in case at every moment you are believing just those things that are supported by your evidence, no matter how weak or poor was the effort at inquiry that resulted in your having just that conception of evidence bearing upon a particular 'target' belief, is far too narrow a sense of rationality to characterize what it means to maximize epistemic value. Its narrowness is exacerbated by the "all-or-nothing" view that Feldman and Conee take, that disallows degrees of 
belief in favor of evidential 'fit' falling neatly into one of three doxastic attitudes: belief, disbelief or suspension of judgment.

This "too narrow" objection to the evidentialist's proposed reduction of epistemic value to synchronic epistemic rationality seems to us obviously true, though its importance isn't fully explored in the literature. That it is solely the relationship, at a given time, between one's evidence and a proposition considered a candidate for belief (or disbelief) that is of epistemic importance is a non-starter. Richard Foley (1988) was essentially right that there are elliptical standards of rational belief proposed by philosophers of science and by traditional epistemologists, the two groups being concerned with different kinds of rational belief. The former adopt a social or intersubjective perspective that is attuned to diachronic rationality, while the methodological individualism of the latter focuses upon the synchronic rationality of the agent at a given time-slice. "[G]iven the elliptical nature of claims of rationality," Foley points out, "there need be no genuine conflict here" (Foley 1988, 136). We think that wanting to do well over time is something that applies to both our intellectual and our prudential goals. But Conee and Feldman seek to justify the reductionist claim that only synchronic epistemic rationality matters in epistemic evaluation of the agent. The strategy they employ to this end is to insist that responsibility or irresponsibility in inquiry raises "moral or prudential questions rather than epistemic questions" (Conee and Feldman 2004, 178; emphasis added). For them what we provocatively term diachronic epistemic rationality, isn't epistemic at all: "Whether I should be a better epistemic agent is always a practical question. The narrower question about what I should believe now, the question I want to focus on, is the central epistemological question" (Feldman 1988, 252; see also his 2002). Their stance reflects what the inquiry pragmatist sees as an overtly rationalistic view of agency, which would be persuasive only if an adequate theory of evidence can justifiably bracket questions concerning the quality of the agent's inquiries. That "[e]videntialism provides no guidance about what to do," and that its account of cognitive success is indifferent to how diligent or slothful were the agent's inquiries and reflections, arguably tell us far more about the inadequacies of internalist evidentialism than about the purported lack of genuinely epistemic value in our zetetic or inquiry-focused activities.

Among the insights of reliabilist externalism, as it caught hold during the post-Gettier era, is that the etiology of belief matters. For reliabilists, proper appraisal of the epistemic status of particular beliefs requires that we be confident in identifying a reliable process type as giving rise to a token belief. Furthermore, reliabilism's recognition of the importance of etiology at least implicitly acknowledges the need for a diachronic component in any account of knowledge and epistemic justification. Both virtue reliabilists and virtue responsibilists are concerned with diachronic goals. Theoretic understanding is entirely caught up with it, even if there are thin subjective and objective senses of being propositionally justified that are not. However, Richard Feldman and 
Earl Conee contend that synchronic epistemic rationality is the only source of properly epistemic value. This reductionist view denies that factors external to the cognitive agent's ken (i.e., bearers of reliability and factors relevant to the etiology of beliefs) can be sources of epistemic value. This view also denies epistemic import to considerations external to the present time-slice at which $\mathrm{S}$ evaluates the available evidence for some proposition that stands as a candidate for belief (or disbelief). As such, it also denies that diachronic epistemic rationality can be a source of properly epistemic value.

Dewey taught us that to move beyond the divide issue in ethics requires an approach where action and character are equally central objects of moral evaluation, and neither one is to be taken as the exclusive or even more basic concern of moral philosophy. Perhaps similarly, then, to move beyond the divide issue between the belief-focused evaluations of internalists and the agentfocused evaluations of virtue epistemologists requires an approach where both kinds of evaluation are acknowledged to have central roles important to epistemic success. This is what Conee-Feldman evidentialism denies. The claim that synchronic epistemic rationality provides a complete account of epistemic justification, and that this in turn is what constitutes epistemic rationality, is sufficiently-well refuted by Catherine Elgin when she writes,

Our cognitive goal ... is not to ace life's true/false test. It involves forming beliefs (and other attitudes) that we can use as a reasonable basis for inference and action and can responsibly convey to others when interests are cognitive.... Truth value does not determine cognitive value. So to restrict the focus of epistemology to factors that would maximize our prospects of acing the test is unwise. It substitutes a thin conception of knowledge for thicker conceptions of epistemic states that are more valuable (Elgin 2008, 386 and 371).

\section{Zetetic Responsibilism and the Epistemic Value of Diachronic Rationality}

One motivation for the present paper is to state a case for diachronic rationality's contributions to epistemic value. The further connection between diachronic rationality and intellectual virtues should be obvious since virtues like intellectual conscientiousness, honesty, open-mindedness, etc. do not apply straightforwardly to the appraisal of beliefs, especially if the justification for beliefs is taken apart from the epistemic situation of a particular agent. Instead, virtues of the sort just mentioned make us good at inquiry (compare Baehr 2006, 2010; Elgin 2006, 2008). In the previous section we acknowledged that synchronic epistemic rationality, once properly reformulated, serves as a source of epistemic value with respect to some distinctively human and higher epistemic standings, including theoretical understanding. But this proper reformulation requires the rejection of several tenets espoused by Conee and Feldman: namely, at least, their internalist account of epistemic justification, 
their 'moderate' deontologism, their account of epistemic value-maximization, and their claim that the source of diachronic rationality's value is practical and non-epistemic.

In the present section we defend our claim that diachronic epistemic rationality is a third independent source of epistemic value. As we have already seen, internalists like Conee and Feldman contend that synchronic epistemic rationality is the only source of properly epistemic value. This view denies that factors external to the cognitive agent's ken can be sources of epistemic value. It also denies that diachronic epistemic rationality can be a source of epistemic value. It is our view that it is an important source of epistemic value. What, then, is the value of diachronic epistemic rationality? And why is this value best considered an independent source of epistemic value?

Of central importance to the epistemic axiology that we are presently developing is that a "zetetic" or inquiry-based conception of virtue can recognize a wide variety of epistemic goods without reducing the value of those many goods to their contribution to the value of any one particular epistemic good (e.g., knowledge or epistemic justification). Among the goods recognized by our zetetic conception of virtue is the value of diachronic epistemic rationality. Our view is that responsible inquirers are epistemically better off than 'merely' reliable and 'merely' synchronically rational agents because the former possess and manifest virtues that the latter may lack. From our "zetetic" point of view, a virtue is a habit that can be relied upon as a means for successfully conducting responsible inquiry; and this is the primary source of virtue's unique epistemic value. To say that a habit is reliable is really to say two things. First, it is to say that the habit has been reliable in environments similar to the ones we now inhabit. Second, it is to say that the habit is to be relied upon in prospective inquiries. This is not to say that the virtues must be fixed and inflexible. On the contrary, the habits that facilitate inquiry over time must be flexible enough to respond to new and novel problems (Rice, 1996). Indeed, the value of zetetic virtue across time does not imply the static identity of the virtue across time. The habits possessed by a novice, twelve-year-old inquirer will not (and ought not) be identical to the habits possessed by an advanced and mature inquirer. In large part, the difference corresponds to changes in the sophistication and complexity of the subject matters of inquiry, as well as the sophistication and complexity of the resources (observational, evidentiary, technological, etc.) available to the mature inquirer. Nevertheless, there is continuity in zetetic advancement. Properly cultivated, the early habits serve as cruder resources for the development over time of more refined zetetic habits. Thus, unlike "routine" habits, which fix human thought and action into unreflective ruts, intelligent habits are flexible, adaptable habits. John Dewey puts the point well when he says, "the intellectual element in a habit fixes the relation of the habit to varied and elastic use, and hence to continued growth" $(M W 9,53)$. 
The idea that virtues facilitate growth clearly reveals the sort of diachronic epistemic rationality that makes a unique contribution to our epistemic axiology. Inquiry, when conducted responsibly, is a self-correcting process, one that subjects the methods, evidences, and outcomes of past inquiries to scrutiny. Evidentialist epistemic normativity is recognized as valuable from the point of view of inquiry; but the reflective virtues that successfully facilitate responsible inquiry also serve us well in our critical evaluations of past inquiries, and in our improvements of future inquiries. These flexible, reflective virtues help inquirers to improve upon the methods and habits that have governed past inquiries. In so doing, the virtues tend toward their own improvement, and toward the improvement or growth of the inquirer. It is here, in virtue's contribution to growth, that the relationship between virtue and human flourishing is most evident. Underlying Feldman and Conee's insistence that diachronic considerations are essentially non-epistemic is the assumption that theoretical and practical norms are distinct in kind. Our inquiry-based approach to epistemic rationality assumes no distinction between natural kinds of reasons or virtues. Contrary to the implicit suggestion of evidentialists, thinking is not something that simply happens between one's ears. Thinking involves the performance of various operations - including motor, observational, and ideational operations. Inquiry, as a medium of thought, is a transaction with our environments; it is a response to our environment by which we in turn make the environment respond. Successful inquiry aims to establish and purposively control relationships among the objects and potencies available within the environment, rendering the environment more intelligible and inhabitable. As such, the virtues that facilitate inquiry are not simply stable habits; they are also stabilizing habits. An orderly world is not simply a precondition for the cultivation and exercise of virtue but also an achievement of inquiry. Thus, the possession and exercise of virtue contributes to the conditions for its own continued possibility and value.

Dewey, in our view, contributed significantly to moral theory in the twentieth century by critiquing consequentialism, deontology, and "virtue ethics" (in its narrow construal) as one-sided systems, only one of which the agent needs in problematic situations of moral reflection and action. Our claim is that there are also at least three factors that should be acknowledged to be independent sources of epistemic value. What each contributes of permanent value shows their independence, and this in turn shows the need for a pluralist epistemological axiology (Section 7) Our account of epistemic goodness is one where the synchronic and diachronic forms of rationality (and personal justification) are goods internal to inquiry, strongly related to the value of cognitive achievements (final value) as well as to intellectual growth and flourishing.

Finally, an inquiry-based conception of virtue expands the scope of our concern enough to include more than just epistemic values. The habits involved in successful inquiry help us to secure and enjoy many kinds of valuable objects 
and activities in all areas of human experience. The problems that it is the business of inquiry to solve may be classified as moral, epistemic, political, or as problems of any other sort. But such classification is itself a part of the process of inquiry. Consequently, any distinctions between kinds of reasons or kinds of virtues are themselves conclusions or outcomes of inquiry. It is for these reasons that we see our "zetetic" approach to virtue as part of a still broader theory of value. It underlines the lessons of externalism, but goes further than agent reliabilist VE by insisting that evaluations of epistemic rationality are tied to evaluations of the inquiry-involving or zetetic activities of the agent. The agent's diachronic epistemic rationality is the factor among these three that most clearly addresses concerns about achievements-through-inquiry. The reflective virtues, as diachronic traits of character that bear upon the quality of our efforts at inquiry, contribute greatly to epistemic goodness or value in the sense that relates it to final value, or the kind of value shared by genuine achievements of all kinds (Pritchard 2009a).

\section{Pluralism in Focus}

The foregoing sections describe Dewey's approach to reflective morality, and what appear to us the most natural epistemic analogues of his "three independent factors in morals." We provided reasons to affirm that each of the three factors agent reliability, synchronic, and diachronic epistemic rationality - contributes something important to epistemic evaluations of agents and their beliefs, and that epistemology as a field of study would be impoverished if any one of these factors gets ignored. Moreover, we argued that the exclusivist claims that attend the systems built upon a privileging of any one of the three are all of them unconvincing. Externalist reliabilism, internalists evidentialism, and virtue epistemologies of the robust sort are not the "complete" accounts of epistemic normativity they claim to be, and our argument if cogent should have a strongly deflationary implication for the volatile yet under-motivated debates between them. In this concluding section we reveal some important implications of this negative argument, but our primary objective is to provide a positive account of the kind of epistemic pluralism that we advocate. Our axiological epistemic value pluralism consists of two core claims. On the one hand, we conceive of our three factors as functionally independent from one another. But the functional independence of these factors does not imply their isolation from one another. On the contrary, we view the three factors as reciprocally augmentative of one another.

We have described our account of epistemic normativity as "pluralistic," but this can mean various things. Some epistemologists who describe themselves as epistemic value pluralists may intend opposition to veritism and other forms of epistemic value monism that view true belief as the single "core" goal of intellectual life. While veritists commonly accept just enough of the pragmatist critique to qualify this core goal as "interesting" true belief, virtue 
responsibilists (including Hookway, Elgin, Napier, and Zagzebski) hold that this conception of epistemic ends is not comprehensive enough. Responsibilists often claim that epistemology should widen its scope to include theoretical understanding and wisdom among the several desirable goals of intellectual life. For some of these authors, a pluralistic account of epistemic goods is supported by a somewhat eudaimonistic account of the intellectually good life in which true belief plays a still vital but more limited role in our overall cognitive economy. Let's call these versions of epistemic value pluralism "teleological pluralism," since they identify a number of desirable epistemic goals.

Although our account of epistemic value pluralism is consistent with teleological pluralism, the philosophical upshot of our novel approach has not been the need to accept teleological pluralism (a plurality of valuable aims) but, more precisely, axiological pluralism (a plurality of sources or springs of value). Our epistemic analogue of Dewey's moral pluralism calls into question three leading theories of epistemic normativity: reliabilist externalism, evidentialist internalism, and motivation-based or "pure" virtue epistemologies. The onesidedness of these competing systems does not rest upon the poverty of their accounts of epistemic aims, but rather on the poverty of their reductive accounts of the sources of epistemic normativity or goodness. Axiological pluralism corresponds most closely to the critique of reliabilists, internalists, and virtue epistemologists who might claim that their approach provides a full account of epistemic normativity. Its positive claim parallel's Dewey's by recognizing independent "springs" of epistemic value. ${ }^{1}$

The reciprocal relationship between agent reliability, synchronic epistemic rationality, and diachronic rationality reveals the non-reductive side of our epistemic value pluralism. Within the ongoing process of inquiry, each of the three factors we have identified supports the other two. Thus, no single factor carries the whole load of epistemic value, and no one factor serves as the supremely final value toward which the other two aim. In this way, the reciprocal relationship among the factors grounds our rejection of both foundational and teleological reductivism. Agent reliability, synchronic epistemic rationality, and diachronic epistemic rationality are parts of the process of every responsible inquiry. But it is a mistake to conceive of these three factors as wholly distinct and insulated processes themselves. It is similarly a mistake to view inquiry as a process that unilaterally builds upon or proceeds from a foundation or starting point in either agent reliability, synchronic epistemic rationality, or in diachronic epistemic rationality. The three factors that we have identified in this essay are not steps in a unilateral process, but rather reciprocally related features of the ongoing process of inquiry.

Diachronic epistemic rationality may lead to the cultivation of habits that help us to manage luck better than we have in past inquiries. It is a source of "thick" epistemic values, including epistemic responsibility in inquiry, and evidence growth (Axtell and Carter 2008; Axtell 2008; Elgin 2008). If ongoing 
inquiry occasions increased awareness of the potential impact of veritic and/or environmental luck and makes the inquirer take this into account when forming beliefs in future inquiries, then the inquirer grows as a responsible epistemic agent by strengthening her agent reliability. In like fashion, awareness of past instances of knowledge-precluding luck may be internalized and incorporated into evidentiary and justificatory considerations, thus contributing to synchronic or propositional justification. Similarly, diachronic epistemic rationality may contribute to synchronic epistemic rationality by making the inquirer more diligent in the search for evidence, more sensitive to the salience of discovered evidence, and more assiduous in the processing of that evidence.

But if these factors are so intimately related and mutually supportive of one another, then in what sense are they "independent" factors? To understand each of the three independent factors, qua primary springs or sources of epistemic goodness, we need to remove them from the setting of the reductionist theories that distort them even as they claim exclusive conceptual or explanatory primacy for them. Thus "synchronic rationality" is epistemically valuable, but its contribution to epistemic value is distorted by claim of internalists like Conee and Feldman that it constitutes a complete account of epistemic responsibility. Diachronic rationality is similarly distorted by those robust forms of virtue epistemology that strictly identify value and virtue; and a reliable causal etiology of belief is valuable, though its contribution to epistemic value, too, is distorted by those reliabilist theories that ignore value-driven concerns or that succumb to the naturalistic temptation of supposing that we can do away with the need to talk about good reasons, and talk only about causes of belief in a process sense.

The three factors here identified function as independent factors in the practice of epistemic evaluation. By claiming that our three independent factors are functionally distinct we aim to say something about the roles that these factors play in those epistemic inquiries that aim to turn out evaluative judgments about epistemic goods. We thereby ground the independence and reflexivity of our three factors in epistemic practice, consistent with the way that pragmatists see theorizing as an extension of our practices, and norms as reflecting values that come into play in those practices rather than as selfcontained or developing in isolation from them (Lekan 2006, 253). As explained earlier, each of our three factors has proven useful for making evaluative epistemic judgments. Each factor offers a distinct focus around which to organize epistemic evaluations. To put it another way, each factor represents a different evaluative tool to help us make judgments about persons' claims to a host of epistemic goods (including knowledge, justification, virtue, understanding, and so on). However, since each factor is a part of every inquiry, which factor we appeal to when adjudicating claims to epistemic goodness is to be determined by our aims or interests in particular cases. To borrow a term from Daniel Dennett, we can adopt an agent-reliability "stance," a synchronic rationality "stance," or a diachronic rationality "stance" toward the claim in 
question. It is possible that it is more appropriate to adopt one of these stances rather than either of the others in certain contexts. Indeed, it would be helpful to know whether there are types of cases in which it is more appropriate to appeal, for instance, to agent-reliability than it is to appeal to either synchronic or diachronic rationality. It is perhaps possible to describe these types of cases, but we are not prepared to offer the requisite descriptions at this time. However, we suspect that the grounds for distinguishing types of cases are most appropriately located in the aims and interests of epistemological inquirers than in features of particular epistemic situations, conceived independently of those aims and interests. Agent reliability, synchronic epistemic rationality, and diachronic epistemic rationality are independent factors in evaluative epistemic practice. Which factor best serves our aims and interests in our epistemic agency and modes of inquiry should function as the desideratum in a given evaluation.

The real contributions of the independent factors approach to epistemic value or goodness remain unrecognized, because treatment of reliability and synchronic and diachronic epistemic rationality have too often been held captive to the reductive ambitions of the various competing accounts of epistemic normativity. We see the situation in epistemology as one of staleness and stalemate over debates that are sustained by these questionable efforts. The tactic of "centralists," for example, always involves the attempt to reduce thick epistemic normativity to one or another thin form (consequentialist or deontological). But even virtue theorists, who are non-centralist in orientation, often make the judgments of a phronomos serve to identify or even define the thin concepts of rightness or justification. The distinctiveness of virtue theory's connection with human flourishing is typically lost when it is treated in this way (Nussbaum 1999). Yet it is not clear that reliability and synchronic and diachronic rationality are related to thick and thin normative concepts in any simple and straightforward way. Furthermore, the internalist/externalist debate is in part directly traceable to a failure to properly distinguish not only between evaluative and deontic concepts, but also between personal, doxastic, and propositional justification (Engel 1992, Turri 2009). One implication of our approach is the need to more properly distinguish these foci and agent and belief evaluation; another is that there may be more of philosophical interest in a phenomenology of inquiry and in the study of habits and strategies needed as resources by agents in the first-personal or zetetic context of inquiry. This second claim seconds Todd Lekan's point that we need to attend more directly "to the causes and conditions of deliberation itself. That is, we need to foster those conditions that equip people with habits that enable effective deliberation" (Lekan 2006, 270, n. 8; Compare Dewey $L W$ 2, 94-95). For the inquiry pragmatist there should be optimism about a "general theory of value" comparing moral, epistemic, and other kinds of value (Axtell 1996, 2009; Olson 2007a, 2007b). There is some interest in this topic, and there is some in empirical studies of agent responsibility and the evidence for or against "robust" and "global" intellectual virtues. But from the present perspective there is 
decidedly less of interest to be found in between these concerns, in the projects of conceptual analysis for propositional knowledge and epistemic justification around which the internalism/externalism debate is shaped.

Our view has some decidedly "deflationary" implications for debates based around the presumed incompatibility of accounts that focus on the role of any of the three factors. But the axiological pluralism we have endorsed need not be thought to deny altogether the usefulness of mutually-exclusive internalist and externalist conceptual analyses of propositional knowledge and justification. While the reductionistic spirit is certainly present in these and other attempts to define mutually-exclusive conceptual analyses of propositional knowledge, our approach does not preclude them but largely bypasses them, re-focusing debate on a genealogy for knowledge and a phenomenology of inquiry. We don't deny that reliability could still be a crucial requirement for some epistemic states or standings, while other states or standings are best analyzable in terms of certain internalist conditions. ${ }^{2}$ But we think these matters of what the strength of each theory really is and to which central epistemic concepts or concepts each is best applied can only receive the clarity they deserve once the independence and more especially the reciprocity of the three factors is more fully acknowledged. We have therefore been concerned to state the case for this independence, and to articulate what each factor, separately and working together with the others, contributes of permanent value to the life of the intellect.

\section{NOTES}

1. Axiological pluralism is best conceived as antithetical to value reductivism, but not necessarily to a certain kind of value monism, for inquiry functions as the unifying consideration in our study of a plurality of epistemic goods, even if the value of our three factors is not reducible to the contributions they make to inquiry. In other words, while responsible inquiry entails the goods of reliability and synchronic and diachronic rationality, responsible inquiry itself needn't be understood as an additional, independent good.

2. We thank John Greco for this suggestion.

\section{REFERENCES}

Axtell, Guy. 1996. "Epistemic Virtue-Talk: The Reemergence of American Axiology?" Journal of Speculative Philosophy 10: 172-198.

Axtell, Guy. 2007. "Two for the Show: Anti-Luck and Virtue Epistemologies in Consonance." Synthese 158.3: 363-383.

Axtell, Guy. 2008. “Thickies: Pragmatism and Virtue Theory.” Transcript.

Axtell, Guy 2009. “General Theory of Value: 1909-2009.” Typescript. 
Axtell, Guy, and A. Carter. 2008. "Just the Right Thickness: A Defense of Second-Wave Virtue Epistemologies," Philosophical Papers, "Epistemology Through Thick and Thin," 37.3: 413-434.

Baehr, Jason. 2010. "Evidentialism, Vice, and Virtue," in Evidentialism and Its Discontents, ed. Trent Dougherty (New York: Oxford University Press, forthcoming).

Baehr, Jason. 2006. "Character, Reliability, and Virtue Epistemology." Philosophical Quarterly 56: 193-212.

Becker, Kelly. 2008. "Epistemic Luck and the Generality Problem." Philosophical Studies 139: 353-366.

Conee, Earl, and Richard Feldman. 2004. Evidentialism: Essays in Epistemology. Oxford: Oxford University Press.

Dewey, John. 1922. Human Nature and Conduct. New York: Henry Holt and Co.

Dewey, John. 1978. The Middle Works, 1899-1924, ed. Jo Ann Boydston, 15 vols. Carbondale: Southern Illinois University Press.

Dewey, John. 1989. The Later Works, 1925-1953, ed. Jo Ann Boydston, 17 vols. Carbondale: Southern Illinois University Press.

Dougherty, Trent. 2008. "Baehr on Evidence and Virtue." Typescript.

Engel, Mylan. 1992. "Personal and Doxastic Justification in Epistemology." Philosophical Studies 67: 133-150.

Engel, Pascal. 2008. "Epistemic Norms and Rationality.” Typescript.

Elgin, Catherine. 2008. “Trustworthiness.” Philosophical Papers 37: 371-387.

Elgin, Catherine. 2006. "From Knowledge to Understanding," in Epistemology Futures, ed. Stephen Hetherington (Oxford: Clarendon Press), pp. 199-215.

Feldman, Richard. 2002. "Epistemological Duties," in Oxford Handbook of Epistemology, ed. Paul Moser (Oxford: Oxford University Press), pp. 362-384.

Feldman, Richard. 1988. "Epistemic Obligations," Philosophical Perspectives, vol. 2, pp. 235-256.

Foley, Richard. 1988. "Some Different Conceptions of Rationality," in Construction and Constraint, ed. E. McMullin (South Bend, Ind.: University of Notre Dame Press), pp. 123-152.

Greco, John. 2005. "Justification is not Internal," in Contemporary Debates in Epistemology, ed. Matthias Steup and Ernest Sosa (Malden, MA: Blackwell), pp. 257270. 
Hookway, Christopher. 2006. "Epistemology and Inquiry: The Primacy of Practice," in Epistemology Futures, ed. S. Heatherington (Oxford: Clarendon Press), pp. 95-110.

Hursthouse, Rosalind. 1991. "Virtue Theory and Abortion." Philosophy and Public Affairs 20: 223-246.

Lekan, Todd. 2006. "Pragmatist Metaethics: Moral Theory as a Deliberative Practice." Southern Journal of Philosophy 44: 253-271.

Levin, Michael. 2004. "Virtue Epistemology: No New Cures." Philosophy and Phenomenological Research 69: 397-410.

Napier, Stephen. 2008. Virtue Epistemology: Motivation and Knowledge. London and New York: Continuum.

Nussbaum, Martha. 1999. "Virtue Ethics: A Misleading Category?" Journal of Ethics 3: 163-201.

Olson, Philip. 2007a. “Dewey's Virtues,” SAAP meeting paper. Transcript.

Olson, Philip. 2007b. The Virtues of Flourishing Rational Agents. PhD dissertation, Emory University

Pappas, Gregory. 2008. John Dewey's Ethics: Democracy as Experience. Bloomington: Indiana University Press.

Pritchard, Duncan. 2003. "Virtue Epistemology and Epistemic Luck," repr. in Moral and Intellectual Virtue, eds. Brady and Pritchard (Oxford: Basil Blackwell, 2003), pp. 106130.

Pritchard, Duncan. 2005. Epistemic Luck. Oxford: Oxford University Press.

Pritchard, Duncan. 2007. "The Value of Knowledge," article in Stanford Encyclopedia of Philosophy, http://plato.stanford.edu/entries/knowledge-value/

Pritchard, Duncan. 2009a. "Knowledge, Understanding and Epistemic Value," Royal Institute of Philosophy Supplement 84 (Cambridge: Cambridge University Press), pp. 1943.

Pritchard, Duncan. 2009b. Knowledge. New York: Palgrave Macmillan.

Rice, Suzanne. 1996. "Dewey's Conception of 'Virtue' and its Implications for Moral Education," Educational Theory 46: 269-282.

Riggs, Wayne. 2008. "The Value Turn in Epistemology," in New Waves in Epistemology, ed. V. Hendricks and D. H. Pritchard (Aldershot, UK: Ashgate), pp. 300-323.

Turri, John. 2009. "On the Relationship between Propositional and Doxastic Justification," Philosophy and Phenomenological Research, forthcoming. 


\author{
Guy Axtell \\ Assistant Professor \\ Department of Philosophy and Religious Studies \\ Box 6943 \\ Radford University \\ Radford, Virginia 24142 \\ United States \\ Philip Olson \\ Visiting Assistant Professor \\ Philosophy Department and Department of Religion and Culture \\ College of Liberal Arts and Human Sciences \\ 219 Major Williams Hall (0126) \\ Virginia Polytechnic Institute and State University \\ Blacksburg, Virginia 24061 \\ United States
}

